\title{
A salvaguarda da diversidade e a defesa da criação
}

\author{
Safeguarding the diversity and the protection of creation
}

\author{
Faustino Teixeira*
}

\begin{abstract}
Resumo
A partir de um desafio lançado pela Comissão Teológica Internacional da EATWOT, em torno do paradigma pós-religional, o texto busca reagir a questões pontuais como a crise das religiões, o colapso dos exclusivismos e a emergência das novas espiritualidades. Na argumentação proposta, verifica-se que de fato está em curso uma crise das "instituições tradicionais produtoras de sentido", sem que isto ocasione necessariamente o desaparecimento da religião, mas uma diversificação no modo de sua presença no tempo. Como ponto de concordância com a proposta, em favor de um novo paradigma pós-religional, há a percepção da irradiação cada vez mais patente de espiritualidades que vão se firmando, mesmo fora dos arranjos religiosos. Essa presença talvez seja um traço peculiar e novidadeiro desse novo milênio. Ao final, busca-se sinalizar o diálogo, a salvaguarda da diversidade e a defesa da criação como passos essenciais na nova configuração das espiritualidades e religiões no tempo atual.
\end{abstract}

Palavras-chave: Religião. Espiritualidades. Diálogo. Criação. Terra.

\begin{abstract}
From a challenge of the International Theological Commission of EATWOT, with regard to post-Religional paradigm, this text intends to respond to specific issues such as the crisis of religions, the collapse of exclusiveness and the emergence of new spiritualities. Our argument proposal notes that in fact there is an ongoing crisis of "producing traditional institutions of meaning", without this entailing the disappearance of religion, but a diversification in the way of his presence in time. As a point of agreement with the proposal in favor of a new post-Religional paradigm, there is the perception of irradiation increasingly patent spiritualities that will steadying, even outside of the religious arrangements. This presence may be a peculiar trait and novidadeiro this new millennium. At the end, we seek to signal the dialogue, the safeguarding of diversity and the protection of creation as key steps in the new configuration of spiritualities and religions at the present time.
\end{abstract}

Keywords: Religion. Spiritualities. Dialogue. Creation. Earth

Artigo recebido 02 de novembro de 2014 e aprovado em 06 de março de 2015.

* Doutor em Teologia pela Pontifícia Universidade Gregoriana de Roma. Professor no Programa de Pós-Graduação em Ciência da Religião da Universidade Federal de Juiz de Fora. Pesquisador do Conselho Nacional de Desenvolvimento Científico e Tecnológico (CNPq). Consultor da assessoria do Instituto de Estudos da Religião (Iser). País de origem: Brasil. E-mail: fteixeira@uaigiga.com.br. 


\section{Introdução}

Responder ao convite de Horizonte - Revista de Estudos de Teologia e Ciências da Religião para abordar esta complexa questão de um possível paradigma pós-religional foi para mim desafiante. Em primeiro lugar, por não estar muito certo sobre a plausibilidade desta hipótese, embora veja a importância da discussão que ela levanta. Em segundo lugar, pelo espaço que se abre para levantar novas indagações a respeito do momento atual que envolve tanto as religiões como as espiritualidades, mas também sobre a dinâmica em curso sobre o novo passo relacional dos seres humanos, neste momento, que alguns vêm designando como Antropoceno, ou seja, uma nova era do humano, enquanto agente geológico, caracterizada por seu impacto sobre a Terra, onde se firmam condições profundamente adversas para o futuro da espécie humana.

Em defesa de um paradigma pós-religional tinha já se posicionado a Comissão Teológica Internacional da EATWOT, em artigo publicado em Koinonia Revista Electrónica Latinoamericana de Teología (COMISIÓN, 2014). É uma discussão que vem sendo levada adiante por um segmento de teólogos, entre os quais destaca-se José María Vigil, que esteve também na ousada iniciativa da Comissão Teológica Latino-Americana da ASETT/EATWOTT em favor de um diálogo criativo da teologia da libertação com a teologia do pluralismo religioso. Foram cinco volumes publicados, com o título amplo Pelos muitos caminhos de Deus. No quinto volume, publicado em 2011, propunha-se o tema de uma teologia planetária e multirreligiosa (uma teologia interfaith). Como sua marca, uma perspectiva leiga, livre das amarras institucionais, não inclusivista e de perfil cosmo-biocêntrica, voltada sobretudo para "humanizar a humanidade e o planeta" (VIGIL, 2011, p. 276 e 277). Este quinto volume veio precedido de uma consulta realizada com teólogos de diferentes religiões e de várias partes do mundo, levantando uma série de indagações, entre as quais a possibilidade de um caminho previsto em direção a algo além de uma "teologia confessional pluralista". A consulta vem concluída com algumas "perguntas concisas", onde se lança a 
hipótese do traço pós-religional de uma espiritualidade interfaith (VIGIL, 2011, p. 17-18).

Esta proposta de um paradigma pós-religional vem também defendida, com seus traços peculiares, pelo teólogo espanhol Marià Corbí (1932 - ), diretor do Centro de Estudo das Tradições Religiosas de Barcelona (CETR). Trata-se de um autor ainda pouco conhecido no Brasil, e que vem se dedicando ao estudo das transformações geradas pelas sociedades pós-industriais, em particular o seu impacto nas tradições religiosas. Na perspectiva por ele defendida, nas atuais sociedades de conhecimento, as religiões deixam de ocupar a centralidade que encontravam nas sociedades pré-industriais, e o seu interesse vem substituído pela busca de espiritualidade em variegadas formas de expressão. Como ele sublinha, "a grande maioria dos jovens não quer saber nada de religião. Para eles, a religião não é sequer um problema. Nem a consideram nem a combatem, pois, para os jovens, a religião é só coisa de tempos passados e de gerações passadas" (CORBÍ, 2010, p. 15). Mas esse desinteresse pela religião não traduz um desencanto com a espiritualidade e com a busca diversificada de novos caminhos de sensibilização e busca interior. Isto é também um fenômeno recorrente, entre os jovens.

Este é um tema importante, que envolve não apenas os países da Europa, onde as igrejas encontram-se vazias e os agentes religiosos tradicionais perdem o seu prestígio cultural, mas firma-se igualmente em países do Terceiro Mundo e em desenvolvimento onde o fenômeno dos "não afiliados" ou "sem religião" firma-se a cada década de forma singular e importante.

\section{A crise das "instituições tradicionais produtoras de sentido"}

Não há como negar no tempo atual a presença de uma crise nas instituições religiosas tradicionais, e de modo muito particular no cristianismo. Isto ocorre não apenas na Europa, mas também em parte substantiva das Américas. Um olhar mais abrangente capta essa sangria de participação, que vem corroborada pelo crescimento dos "não afiliados" nas várias partes do mundo. De acordo com o 
relatório do Pew Research Center, publicado no final de 2012, cerca de 16,3\% da população de nosso globo terrestre enquadra-se nesta categoria, com uma presença importante em países como a China, Japão e Estados Unidos (PEW RESEARCH CENTER, 2012). No Brasil, os "sem religião" firmam-se como terceira força na declaração de crença do Censo Demográfico, como ocorreu na divulgação dos dados do Censo de 2010. Eles somam cerca de 15,3 milhões de pessoas, ou seja, 8\% da população geral (TEIXEIRA, 2013, p. 27).

Buscando explicar o refluxo das religiões tradicionais no Brasil, com base no Censo de 2000, o sociólogo Antônio Flávio Pierucci justifica tal situação com o clima intaurado nas sociedades pós-tradicionais, com a crise das filiações rotineiras:

\begin{abstract}
Nas sociedades pós-tradicionais, et pour cause, decaem as filiações tradicionais. Nelas os indivíduos tendem a se desencaixar de seus antigos laços, por mais confortáveis que antes pudessem parecer. Desencadeia-se nelas um processo de desfiliação em que as pertenças sociais e culturais dos indivíduos, inclusive as religiosas, tornam-se opcionais e, mais que isso revisáveis, e os vínculos, quase só experimentais, de baixa consistência. Sofrem, fatalmente, com isso, claro, as religiões tradicionais (PIERUCCI, 2004, p. 19).
\end{abstract}

Alguns acreditam que inclusive o termo religião não consegue mais dar conta dos caminhos trilhados pelos novos buscadores da fé. É o caso do antropólogo Carlos Rodrigues Brandão, que prefere falar em "sistemas de sentido". Em texto biográfico, onde visa traçar seu itinerário de buscador, Brandão levanta uma questão que se coloca com cada vez mais pertinência para muitas pessoas que, como ele, vivem uma "diáspora de fé". São pessoas que descobrem, com angústia e perplexidade, que lhes "falta um nome" para definir o universo específico de sua crença em tempos de tantas mudanças. $\mathrm{O}$ antropólogo carioca traduz de forma muito feliz o sentimento de muitos de seus contemporâneos: 
Está ocorrendo algo que a todos nós parece evidente, só que ainda pouco compreensível: tal como outros campos sociais e simbólicos dos mundos em que vivemos nossas vidas, o campo da religião 'já não é mais como era `. E não apenas porque mudam as porcentagens dos censos e as variações das alternativas de escolhas e formas de fé, de estilos de crença e de modos de vida religiosa e/ou espiritual. Talvez a pergunta essencial não seja 'quem está crendo no que ', mas de que plurais maneiras pessoas que 'creem no mesmo' estão participando diferencialmente de uma mesma fé, de uma mesma crença, de uma mesma religião, de uma mesma espiritualidade (BRANDÃO, 2012b, p. 76-77).

Não são poucos itinerantes, como Brandão, que buscam novas formas de viver a religião ou a espiritualidade. Esse campo da busca axiológica vem sendo tecido por singular diversidade nas formas de conceber, crer e praticar a experiência do sentido, o que se dá dentro e fora das práticas religiosas usuais. Um clássico livro publicado na Alemanha em 1990, depois traduzido ao espanhol em 1992, abordava justamente esta questão das modalidades da crença no tempo atual. Nesta obra, diversos intelectuais, artistas, religiosos e pensadores buscaram responder a uma simples questão: Em que creio eu ? Dentre os que responderam: Hans Albert, Shalom Ben-Chorim, Keith Jarret, Karl Popper, Fernando Savater, Peter Singer e Dorothee Sölle (ALBERT et al, 1992). No compasso das respostas, uma sensação comum: da permanência em nosso tempo do eterno problema da busca do fundamento e do sentido da vida humana. E também a consciência da quebra das barreiras rígidas e dogmáticas e da importância essencial da liberdade. Curiosamente, um dos grande vaticanistas da atualidade, Luigi Accattoli, reconhece como uma das mais singulares novidades aportadas pelo papa Francisco está a defesa da liberdade, bem como a inaceitável "ingerência espiritual na vida da pessoa" (ACCATTOLI, 2014, p. 117).

Estamos diante de algo que é incontestável: a insatisfação face às instâncias tradicionais de sentido e a busca por caminhos novos. Algo inusitado surge nos movimentos individuais e coletivos de busca de sentido. Há também uma demanda por novas leituras, que permeiam e avançam para além da perspectiva teísta, como também lembrou Carlos Rodrigues Brandão: 
Quando converso com vários amigos que foram como eu cristãos católicos engajados em algum movimento de igreja vejo que uma soma considerável deles (eu incluído) está precisando agora realizar uma espécie de releitura não teísta em sua fé para poder se manter ainda cristão, mesmo que já não mais restritamente... católico. Muitos de nós precisamos crer que o próprio Jesus nunca foi o Cristo; nunca foi um 'deus enviado a Terra para nos salvar de nosso próprio pecado coletivo `, para acreditarmos não na mitologia, mas na substância humana dos evangelhos. Não precisamos mais de um deus-homem milagreiro que 'morreu para nos salvar' , e depois ressuscitou para nos dizer que isso irá acontecer com todos nós (pelo menos com o pequeno rol 'dos salvos '). Precisamos de um homemdeus (justamente porque humano) que, entre vários outros, nos diga palavras de sentido e nos envolva de gestos de ternura... para que saibamos como viver e para onde ir, mesmo que não haja 'um céu para os eleitos`. (BRANDÃO, 2012a, p. 57).

\section{Um jeito diverso de presença do religioso}

Num clássico texto de Durkheim, que reproduz uma conferência realizada em janeiro de 1914, na União dos Livres Pensadores (Paris), ele dizia que enquanto houver sociedade humana haverá religião, entendida como um sistema de forças superiores, dinamogênico, que atua sobre as pessoas e a sociedade. Firmava a ideia de que um tal sentimento, demasiado geral à humanidade, não poderia ser algo ilusório (DURKHEIM, 1969, p. 77).

A teoria sociológica evidenciou esse traço da religião como projeção humana e duradoura. As religiões instituídas são, de fato, "historicamente construídas", e não podem ser concebidas como fundadas na dimensão do humano, como tendem mostrar as análises mais essencialistas. Elas são, na verdade, construções culturais. E o que circunscrevem, como apontou Pierre Gisel, "não se encontra em todas as culturas ou em todas as civilizações" (GISEL, 2011, p. 169). Foi o que igualmente indicou a Comissão Teológica Internacional da EATWOTT, em sua proposta de uma paradigma pós-religional: as religiões não estiveram sempre em cena. As mais antigas, como o hinduísmo, remontam a 4.500 anos. O que sempre esteve presente, adverte o documento, foi o homo spirituales, não necessariamente religioso. 
Há autores que no âmbito da reflexão acadêmica quiseram ampliar esse campo semântico da religião, visando trabalhar com um conceito "lato" de religião, distinto do conceito a que estamos habituados. É o caso de autores como Paul Tillich e Keiji Nishitani. Buscam com sua análise resgatar uma dimensão mais ampla ao termo: seja associando-o à dimensão de profundidade (TILLICH, 1968, p. 96) ou de consciência mais profunda da realidade (NISHITANI, 2004, p. 35-36). Mas tais propostas fogem do objetivo proposto neste artigo. O que buscamos evidenciar aqui é justamente o campo movediço no qual as expressões religiosas hoje se apresentam. A categoria religião vem ganhando, assim, uma "pletora de significados", assim como também o "campo religioso", envolvendo a presença de aspectos que não se enquadram precisamente no âmbito das religiões. Como assinalaram Carlos Steil e Rodrigo Toniol, o conceito mesmo de religião torna-se hoje inadequado para "designar um habitus que se expressa por meio de espiritualidades, filosofias de vida e experiências do sagrado que compõem determinado regime de crer" (STEIL; TONIOL, 2012).

Outra questão se coloca para o analista atento à presença do religioso em nosso tempo atual. A forma movediça e fluida com que ela se apresenta na situação contemporânea. O estudioso francês, Philippe Portier, fala em "mutações do religioso" ao abordar a questão da religião na França contemporêna. Ali se dá, a seu ver, um fenômeno muito interessante. Por um lado, a dessubstancialização do catolicismo, ou seja, seu enfraquecimento institucional. Por outro, o reencantamento da civilização republicana, também tomada pelo influxo da "nebulosa místico-esotérica" ou de uma espiritualidade secular e leiga (PORTIER, 2012).

Estudos realizados na Europa sublinham uma nova configuração do fenômeno religioso. Indicam também a perda do poder de imposição das instituições tradicionais sobre os seus fiéis. Verifica-se a presença sutil de um "religioso difuso" que se irradia pela sociedade. O caminho religioso passa agora, necessariamente, pelas escolhas realizadas. Não há mais garantia da tradição como força de imposição sobre os sujeitos. E a forma de ligação com as instituições é 
muito menos rígida que no passado. Isto não significa a morte das religiões, mas sua presença diferenciada.

Como bem mostrou Jean-Paul Willaime, o avanço da modernidade não ocasionou a morte da religião, mas possibilitou novos arranjos para o seu exercício no tempo. Sublinha a necessidade de romper o esquema tradicional que vincula o avanço da modernidade com o enfraquecimento das religiões. O que se dá em verdade com o avanço da modernidade é a irrupção de novas possibilidades de presença do religioso: "Plus de modernité = du religieux autrement" (WILLAIME, 2012, p. 23).

Não há dúvida, porém, sobre a crescente “desinstitucionalização” da religião no tempo atual. As buscas identitárias e espirituais deixam de ser vividas com a exclusividade do passado. Tornam-se muito mais fluidas e livres. Quebra-se o monolitismo de tradições que se apresentam como imutáveis, firmadas em dispositivos institucionais normativos e rígidos. Como pontuou Pierre Sanchis, "as estruturas sólidas que fundavam, enquadravam, regulavam o universo das experiências religiosas, conferindo-lhes distinção, identidade e conteúdo, não o fazem mais com o mesmo rigor, e até quando se reafirmam com renovado vigor, não o fazem com a mesma abrangência.” (SANCHIS, 2013, p. 13; LENOIR, 2012, p. 5).

\section{Questões em torno de um novo paradigma pós-religional}

Na proposta da Comissão Teológica Internacional da EATWOT em torno do paradigma pós-religional estão em jogo algumas questões bem precisas. Em primeiro lugar, a distinção entre "religioso" e "religional”. Não se fala em fim do “religioso", entendido como “dimensão misteriosa do ser humano". Esta dimensão permanece e anima a dinâmica das espiritualidades que vão se firmando no tempo. O que entra em crise é o "religional”, entendido como o "âmbito das configurações sócio-culturais e institucionais" que conformaram as religiões agrícolas do período neolítico. Essas tradições, sim, sofrem um derradeiro impacto com a nova situação 
cultural que se desdobra com as transformações científicas e o processo de industrialização, iniciados nos séculos XVI e XVII, culminando nas novas sociedades de conhecimento. Marìa Corbí aborda em sua obra o impacto que acompanha a irrupção destas novas sociedades, que segundo ele "vivem da criação de conhecimentos”, estando animadas por inovações substantivas em quatro âmbitos: das inovações científicas, tecnológicas, organizativas e axiológicas (CORBÍ, 2010, p. 158). Para este autor, as religiões, assim como constituídas, não conseguem acompanhar a dinâmica das sociedades desenvolvidas, ficando cada vez mais à margem. Esse descompasso deve-se à forma como às religiões vivem sua experiência da "dimensão absoluta da realidade", mais instrumentadas para responder a desafios das sociedades pré-industriais. O documento da EATWOT segue, em geral, uma lógica semelhante à traçada por Corbí. Também identifica o tempo das religiões com o mundo agrário-neolítico, que tende a soçobrar com a afirmação da sociedade do conhecimento.

Em segundo lugar, o traço exclusivista e de controle ideológico que em geral acompanha o exercício da religião. O documento da Comissão da EATWOT reitera esse traço demasiadamente humano das religiões, surgidas "aqui de baixo", e sujeitas aos efeitos da absolutização. Elas foram tomadas pela sede de absolutização, com a atribuição de sua origem ao próprio Deus. E essa perspectiva foi também sendo minada com a dinâmica da sociedade de conhecimento: "Hoje estamos perdendo a ingenuidade desse caráter absoluto das religiões”, diz o documento. O que antes era verdade auto-evidente, perde sua transparência e passa a ser objeto de discussão, dúvida e contestação. Na nova ocular, as religiões são assim entendidas como um "fenômeno histórico” contingente e limitado.

Em terceiro lugar, a ênfase concedida à espiritualidade, enquanto "dimensão constitutiva humana” (COMISIÓN, 2014; CORBÍ, 2014, p. 690). Trata-se de uma dimensão que antecede às formas de inscrição das religiões e que perdura no tempo, atuando mesmo fora da dinâmica religiosa. Como indica o Documento da Comissão da EATWOTT, "podemos prescindir das religiões, mas não podemos prescindir da dimensão da transcendência do ser humano”. 
A proposta de um paradigma pós-religional tem seus aspectos positivos, como por exemplo a crítica ao modo de inserção das religiões no tempo, aos riscos de exclusivismos e fundamentalismos; a ênfase dada sobre o caráter histórico e contingente das religiões. A linha de argumentação é precisa: as religiões não estiveram presentes desde sempre, não sendo igualmente - por natureza - destinadas a durar eternamente. Ocorre que elas continuam aí, presentes, ainda que em processo contínuo de transformação. Assim como foi um equívoco em tempos passados decretar o fim da religião, em razão do crescimento da secularização, corre-se o risco de repetir algo semelhante, com a indicação da crise da religião em razão da afirmação de uma nova situação cultural com as sociedades de conhecimento. Acho precipitado, no momento, decretar sua falência. Entendo que elas estarão no cenário ainda por muito tempo, como apontam os clássicos como Émile Durkheim ou Peter Berger (BERGER, 2001, p. 19-21). Vejo, sim, que a seu lado estarão vicejantes, e com força crescente, uma gama de espiritualidades, religiosas ou não, respondendo ao fundamental imperativo humano de busca de sentido.

\section{Um tempo de crise do antropoceno}

Com base em reflexões que vão sendo tecidas em âmbito multidisciplinar, considero essencial ampliar o olhar para além da configuração das "novas sociedades industriais de conhecimento, inovação e mudança" - como proposto pelo paradigma pós-religional - e pensar para além do antropocentrismo. Somos hoje provocados a incluir em nosso projeto de defesa do pluralismo a questão fundamental da unificação da diversidade cultural com a biodiversidade. Como mostrou Eduardo Viveiros de Castro, “a diversidade humana, social ou cultural, é uma manifestação da diversidade ambiental, ou natural - é ela que nos constitui como uma forma singular da vida, nosso modo próprio de interiorizar a diversidade 'externa '(ambiental) e assim reproduzi-la” (VIVEIROS DE CASTRO, 2007, p. 256). 
Com a entrada no novo século, nós, os humanos modernos, nos damos cada vez mais conta de que somos mortais e mortíferos. Junto com essa consciência, o início de irradiação de uma percepção nova e urgente: de que pertencemos a vida e não o contrário. Toda a lógica que moveu nossa sede de empreendimentos, também no campo da religião, esteve ainda enquadrada numa perspectiva antropocêntrica. Daí a importância de uma mudança de rumo, que implica a inserção do "ambiente" e das "espécies de companhia" em nossa compreensão do "nós". Isso significa entender que a diversidade é simultaneamente um fato social e ambiental, e que é "impossível separá-los sem que não nos despenhemos no abismo assim aberto, ao destruirmos nossas próprias condições de existência” (VIVEIROS DE CASTRO, 207, p. 257).

Acolher esta diversidade em tom maior é ampliar o desafio dialogal, envolvendo novos e fundamentais parceiros. O grande desafio que vem apresentado é o de habitar dignamente o mundo, acolhendo com alegria a riqueza da diversidade das espécies, reconhecidas agora como portadoras de um valor intrínseco. Para que isto aconteça, é necessário quebrar com a dicotomia que isola o ser humano de seu mundo "lá fora". Habitar o mundo é a condição primeira, que antecede todo e qualquer processo de empreendimento construtivo (INGOLD, 2004, p. 113 e 216).

Os seres humanos não são mônadas isoladas, e muito menos espécies superiores na sua excepcionalidade. O que caracteriza o ser humano é sua teia de relações, sua capacidade de "habitar um devir-com". É no rico processo de interação com as alteridades que o humano ganha vida e brilho. É assim que se constitui, nas relações dinâmicas com as "espécies de companhia" (Donna Haraway). Trata-se de um grave equívoco dissociar as entidades de seu ambiente. Daí se recorrer a um conceito da biologia, o conceito de holobiontes, para mostrar a riqueza das relacionalidades: é nesse processo que vai se firmando uma unidade sempre em construção. 
Há que romper o “circuito narcísico do nós" e deixar-se habitar pela presença de outros coletivos. A fixação na excepcionalidade dos humanos acabou reforçando os etnocentrismos e provocando violência por todo canto. Eduardo Viveiros de Castro sintetizou isto muito bem em entrevista concedida a Eliane Brum:

Tem uma frase que o Lévi-Strauss escreveu certa vez, que é muito bonita. Ele diz que nós começamos por nos considerarmos especiais em relação aos outros seres vivos. Isso foi só o primeiro passo para, em seguida, alguns de nós começar a se achar melhores do que os outros seres humanos. E nisso começou uma história maldita em que você vai cada vez excluindo mais. Você começou por excluir os outros seres vivos da esfera do mundo moral, tornando-os seres em relação aos quais você pode fazer qualquer coisa, porque eles não teriam alma. Esse é o primeiro passo para você achar que alguns seres humanos não eram tão humanos assim. $\mathrm{O}$ excepcionalismo humano é um processo de monopolizaçãoo do valor. É o excepcionalismo humano, depois o excepcionalismo dos brancos, dos cristãos, dos ocidentais... Você vai excluindo, excluindo, excluindo... Até acabar sozinho, se olhando no espelho de sua casa. O verdadeiro humanismo, para Lévi-Strauss, seria aquele no qual você estende a toda a esfera do vivente um valor intrínseco (BRUM, 2014).

O caminho em aberto envolve o resgate essencial da dignidade da diferença. Não há protagonismo do ser humano, há cadeia dialogal, processo dinâmico de aprendizados diversificados. Fala-se hoje com razão na ampliação do quadro da alteridade, com o reconhecimento da dignidade dos viventes e da qualidade de seu valor. Reconhecer isso é ampliar a esfera dos direitos, para além dos direitos humanos: é "reconhecer direitos característicos e próprios daquelas diferentes formas de vida" (BRUM, 2014).

Não são pequenas as barreiras em curso que dificultam esse processo de abertura à diversidade. A forma como o ser humano se inseriu no tempo provocou esta dificuldade, é o que os estudos em curso mostram hoje com muita clareza. Fala-se em Antropoceno ${ }^{1}$ como a era dos humanos, ou seja, uma nova era que se

\footnotetext{
${ }^{1}$ Este termo vem cunhado em 1980 pelo biólogo americano Eugene Stoermer e firma-se no mundo científico com a proposta de sua adoção em dois artigos publicados no boletim do Programa Internacional para a Geosfera-Biosfera (IGBP) e a revista Nature, com a autoria do mesmo Eugene em parceria com o Nobel de Química (1995), Paul Crutzen.
} 
sucede ao Holoceno ${ }^{2}$, marcada pela presença do agente humano como agente geológico, na medida em que sua ação predatória no tempo altera a paisagem do planeta, comprometendo o exercício vital de sua própria espécie e dos outros seres vivos. Ou seja, a humanidade deixa "registros" problemáticos que configuram condições para os parâmetros utilizados na determinação da mudança do tempo geológico da Terra.

Nesta nova Idade da Terra nos deparamos com situações que beiram a calamidade e anunciam um horizonte tenebroso para a humanidade. Os exemplos são múltiplos para expressar a crise ambiental planetária: o choque da regulação planetária com a diminuição e perda da biodiversidade e a desestabilização dos eco-sistema3; o aquecimento global e o encaminhamento para a morte térmica do planeta; a queima dos combustíveis fósseis e sua incidência nas mudanças climáticas; a acidificação dos oceanos, colocando em risco a cadeia alimentar etc.

No Brasil, os índios, que são especialistas em fim de mundo, são os primeiros a levantar sua voz crítica contra os desmandos do Antropoceno, contra esse mundo diminuído e empobrecido. O líder Yanomani, David Kopenawa4, descreve de forma impressionante a situação, em depoimento de 1998:

Nos primeiros tempos, os brancos viviam como nós na floresta e seus ancestrais eram pouco numerosos. Omama transmitiu também a eles suas palavras, mas não o escutaram. Pensaram que eram mentiras e puseramse a procurar minerais e petróleo por toda parte, todas essas coisas perigosas que Omama quisera ocultar sob a terra e a água porque seu calor é perigoso. Mas os brancos as encontraram e pensaram fazer com elas ferramentas, máquinas, carros e aviões. Eles se tornaram eufóricos e se disseram: 'Nós somos os únicos a ser tão engenhosos, só nós sabemos realmente fabricar as mercadorias e as máquinas!'. Foi nesse momento que eles perderam realmente toda sabedoria (KOPENAWA, 1998).

\footnotetext{
${ }^{2}$ A era geológica iniciada há 11,7 mil anos, que coincide com a última idade do gelo.

${ }^{3}$ Para essa questão, tendo em conta o caso particular da Amazônia, cf. NOBRE, 2014.

${ }^{4}$ Impressionante o livro publicado na França com os depoimentos de Kopenawa: Davi Kopenawa \& Bruce Albert. La chute du ciel. Paroles d'un chaman Yanomani. Paris: Plon / Terre Humaine, 2010. A tradução brasileira está em curso, com publicação prevista pela Companhia das Letras.
} 
É curioso observar que não só os índios brasileiros como também os pequenos agricultores vão se dando conta com sua sensibilidade apurada que mudanças estão ocorrendo, e captam que algo sério vem acontecendo:

No calendário agrícola de uma tribo indígena você sabe que está na hora de plantar porque há vários sinais da natureza. Por exemplo, o rio chegou até tal nível, o passarinho tal começou a cantar, a árvore tal começou a dar flor. E a formiga tal começou a fazer não-sei-o-que. O que eles estão dizendo agora é que esses sinais dessincronizaram. $\mathrm{O}$ rio está chegando a um nível antes de o passarinho começar a cantar. E o passarinho está cantando muito antes de aquela árvore dar flor. É como se a natureza tivesse saído de eixo. E isso todos eles estão dizendo. As espécies estão se extinguindo, e a humanidade parece que continua andando para um abismo (BRUM, 2014).

Diante da atuação dos brancos, e sua sede aceleracionista, os líderes indígenas e seus xamãs advertem para os riscos que se apresentam. A leitura que fazem das graves secas ou inundações que vão se sucedendo nas diversas partes do planeta é bem peculiar, sendo interpretados com o registro de suas escatologias: trata-se de uma "vingança sobrenatural". Gaia não é apenas uma mãe-bondosa que acolhe com alegria os seus filhos, mas é também a "intrusa" que reage de forma rebelde e dura aos ataques do Antropoceno. Essa face da "intrusão" de Gaia vem sendo defendida nos últimos anos pela pesquisadora Isabelle Stengers, de modo particular na sua obra "Au temps des catastrophes: résister à la barbarie qui vient" (2009)5. Gaia é assim uma figura "ambígua e complexa" que acorda furiosa neste tempo de catástrofes. Ela é "a transcendência que responde, de modo brutalmente implacável, à transcendência igualmente indiferente, porque brutalmente irresponsável, do Capitalismo" (DANOWSKI; VIVEIROS DE CASTRO, 2014, p. 143). O que se revela é um conflito assimétrico, onde os humanos são muito mais desprovidos diante da força imperativa de Gaia, uma "estranha guerra" onde a derrota já está traçada (LATOUR, 2012, p. 483).

\footnotetext{
${ }^{5}$ A questão dos "mil nomes de Gaia" foi tema de um rico evento no Rio de Janeiro, em setembro de 2014, com a presença de pensadores brasileiros e estrangeiros, entre os quais Bruno Latour, Isabelle Stengers, Vinciane Despret, Antônio Nobre, Eduardo Viveiros de Castro, Déborah Danowski, José Augusto de Pádua, Márcio Santilli e outros. Foram também apresentados vídeos com as falas de Donna Haraway e Elizabeth Povinelli. Foi publicado a respeito em TORRES, 2014 e PONTO DE VISTA, 2014.
} 
A revolta de Gaia traduz assim uma “provocação anti-modernista”, contra os destemperos da ação humana no Antropoceno. Revela também um aceno contra o crescimentismo em curso, acordando nos corações e mentes uma advertência essencial: “O que estamos fazendo com Terra onde a gente vive?”. Trata-se de uma crítica impiedosa aos caminhos necrófilos da humanidade, que protagonizou uma invasão contra si mesma. E são hoje os índios - entendidos aqui em seu sentido lato $^{6}$, os terranos - que voltam ao cenário apontando para os humanos os caminhos possíveis para "viver melhor em um mundo pior".

Há uma parte da espécie, o povo de Gaia, também reconhecido como terrano, que se ergue contra o rumo do tempo e luta contra esta afirmação de um “mundo sem nós”, de um mundo diminuído e desambientado. O povo de Gaia é um povo ligado “ontológica e politicamente à causa da Terra”, e se rebela contra os Modernos (os humanos) em sua sandice desenvolvimentista. Estes preferiram permanecer como humanos no Holoceno. O povo de Gaia não, é um povo que capta o chamado de resistir ao Antropoceno, mesmo situando-se em seu dorso, mas criticamente. O inimigo, na verdade, são os Humanos mesmos.

Da teia que envolve o povo de Gaia participam também muitas vozes das religiões, como é o caso de Dalai Lama e agora também o papa Francisco. Em dois momentos recentes, Francisco lança o seu protesto contundente contra a devastação da terra e o descaso com a criação, como na homilia da celebração realizada no cemitério romano de Verano no início de novembro de 2014; e também no discurso do Encontro Mundial dos Movimentos Populares, ao final de outubro do mesmo ano. Neste último encontro ele falou de três direitos sagrados que marcam a luta dos pobres: a terra, o teto e o trabalho. São direitos que se irradiam do centro do evangelho. Reiterou também que estes direitos não podem se realizar quando se carece de paz e se destrói o planeta. E concluiu afirmando que "todos os povos da terra, todos os homens e mulheres de boa vontade têm que

\footnotetext{
${ }^{6}$ Na visão de Eduardo Viveiros de Castro, os índios "são todas as grandes minorias que estão fora, de alguma maneira, dessa megamáquina do capitalismo, do consumo, da produção, do trabalho 24 horas por dia, sete dias por semana" (BRUM, 2014).
} 
levantar a voz em defesa desses dois dons preciosos: a paz e a natureza" (PAPA FRANCISCO, 2014a)7.

\section{Conclusão}

A proposta teológica em favor de um paradigma pór-religional aventa a questão de que as religiões não são eternas, não duram para sempre. Há um traço de verdade nessa reflexão ao sinalizar que as religiões são "fragmentos" e estão marcadas pelo sulco da contingência e da impermanência. Tudo bem! Não há dúvida sobre isso. Mas diante do desafio maior que está adiante, da crise ambiental planetária, elas são convocadas a uma presença mais viva no tempo e ao imperativo dialogal entre si. Isto vale também para as espiritualidades que vão surgindo por todo canto. Religiões e Espiritualidades são desafiadas a alinharem-se com os terranos na luta em favor da salvaguarda da criação. Firma-se uma nova aliança, que irmana as diversas "espécies de companhia" num empenho comum em favor da Vida. Seguindo a pista aberta por Donna Haraway, a reação dos terranos envolve o desafio "de habitar um devir-com", numa responsabilidade partilhada. Assumir a condição de "terranos” num Antropoceno que se revela ameaçador.

\footnotetext{
${ }^{7}$ Discurso também publicado no Portal do IHU: IHU-Notícias, de 29 de outubro de 2014. E para a homilía no Cemitério de Verano, ver PAPA FRANCISCO, 2014b.
} 


\section{REFERÊNCIAS}

ACCATTOLI, Luigi. Il vescovo di Roma. Bologna: EDB, 2014.

ALBERT, Hans et al. En qué creo yo. Torres de San Lamberto: Yalde, 1992.

BERGER, Peter. La désécularisation du monde: un point de vue global. In: BERGER, Peter. (Dir.). (Ed.). Le réenchentement du monde. Paris: Bayard, 2001. p. 13-36.

BRANDÃO, Carlos Rodrigues. A emergência do indivíduo e as novas formas de viver a religião. IHU-Online, ano XII, n. 401, p. 54-58, 03 set. $2012 a$.

BRANDÃO, Carlos Rodrigues. Quem fomos nós? Quem somos agora? Sobre alguns silêncios e alguns assombros a respeito de territórios e caminhos interiores de fé e de destino. In: MARIN, Jérri Roberto (Org). Religiões e identidades. Dourados: Editora UFGD, 2012b. p. 35-90.

BRUM, Eliane. Diálogos sobre o fim do mundo. El País, 29 sep. 2014 (Entrevista com Eduardo Viveiros de Castro e Déborah Danowski. Disponível em:

<http://brasil.elpais.com/brasil/2014/o9/29/opinion/1412000283_365191.html>. Acesso em: 01 nov. 2014.

COMISIÓN Teológica Internacional de la EATWOT. Hacia un paradigma pos-religional propuesta teológica. Koinonia. Revista Electrónica Latinoamericana de Teología, Cidade do Panamá, n. 424. Disponível em: <http://servicioskoinonia.org/relat/424.htm>. Acesso em: 31 out. 2014.

CORBÍ, Marià. El caminho interior. Más allá de las formas religiosas. Barcelona: Planeta, 2001.

CORBÍ, Marià. Para uma espiritualidade leiga. Sem crenças, sem religiões, sem deuses. São Paulo: Paulus, 2010.

CORBÍ, Marià. Una espiritualidade no religiosa desde la tradición cristiana. Horizonte, Belo Horiozonte, v. 12, n. 35, p. 688-715, jul./set. 2014.

DANOWSKI, Déborah; VIVEIROS DE CASTRO, Eduardo. Há mundo por vir? Ensaio sobre os medos e os fins. Florianópolis/São Paulo: Cultura e Barbárie/Instituto Socioambiental, 2014.

DURKHEIM, Émile. Le sentimento religieux à l' heure actuelle. Archives de sociologie des religions, Paris, n. 27, p. 73-77, janvier/juin 1969.

GISEL, Pierre. Teologia e ciências das religiões: por uma oposição em perspectiva.

Perspectiva Teológica, Belo Horizonte, v. 43, n. 120, p. 165-192, maio/agosto 2011.

INGOLD, Tim. Ecologia della cultura. Roma: Meltemi, 2004. 
KOPENAWA, Davi; ALBERT, Bruce. La chute du ciel. Paroles d'un chaman Yanomani. Paris: Plon/Terre Humaine, 2010.

KOPENAWA, Davi. Descobrindo os brancos (depoimento colhido e traduzido por Bruce Alberto na maloca Watoriki, em setembro de 1998). Disponível em:

<http://pib.socioambiental.org/files/file/PIB_verbetes/yanomami/descobrindo_os_bran cos.pdf >. Acesso em: 01 nov. 2014.

LATOUR, Bruno. Enquête sur les modes d'existence. Une anthropologie des modernes. Paris: La Décourvert, 2012.

LENOIR, Frédéric. Les métamorphoses de la foi. Le monde des religions, Paris, n. 55, p. 5, septembre/octobre 2012.

NISHITANI, Keiji. La religione e il nulla. Roma: Città Nuova, 2004.

NOBRE, Antonio Donato. O futuro climático da Amazônia. Relatório de avaliação científica. Disponível em:

<http://www.socioambiental.org/sites/blog.socioambiental.org/files/futuro-climatico-daamazonia.pdf>. Acesso em: 31 out. 2014.

PAPA FRANCISCO. Discorso del Santo Padre Francesco ai partecipanti all'incontro mondiale dei Movimenti Popolari. Disponível em: <http://w2.vatican.va/content/francesco/it/speeches/2014/october/documents/papafrancesco_20141028_incontro-mondiale-movimenti-popolari.html>. Acesso em: 01 nov. 2014 .

PAPA FRANCISCO. Omelia del Santo Padre Francesco. Solennità di Tutti i Santi. Cimitero Del Verano, Sabato, o1 Nov. 2014. Disponível em:

<http://w2.vatican.va/content/francesco/it/homilies/2014/documents/papa-

francesco_20141101_omelia-ognissanti.html>. Acesso em: 01 nov. 2014.

PEW RESEARCH CENTER. The Global Religious Landscape - A report on the Size and Distribution of the World's Major Religious Groups as of 2010, dez./2012. Disponível em: <http://www.pewforum.org/2012/12/18/global-religious-landscape-exec/>. Acesso em: 31 out. 2014.

PIERUCCI, Antônio Flávio. "Bye bye, Brasil” - O declínio das religiões tradicionais no Censo 2000. Estudos Avançados, São Paulo, v. 18, n. 52, dezembro 2004. p. 17-28. (Dossiê Religiões no Brasil - USP).

PONTO DE VISTA. Olhar pessoal: Os mil nomes de Gaia. 07 out. 2014. Disponível em: <https://amnerisamaroni.wordpress.com/2014/10/o7/olhar-pessoal-os-mil-nomes-degaia/>. Acesso em 31 out. 2014.

PORTIER, Philippe. Les mutations du religieux dans la France contemporaine. Social Compass, Louvain, v. 59, n. 2, p. 193-207, june 2012. 
SANCHIS, Pierre. Prefácio. In: TEIXEIRA, Faustino; MENEZES, Renata (Org.). Religiões em movimento. O censo de 2010. Petrópolis: Vozes, 2013. p. 11-16.

STEIL, Carlos; TONIOL, Rodrigo. A crise do conceito de religião e sua incidência sobre a antropologia. In: GIUMBELLI, Emerson; BÉLIVEAU, Verónica Gimenéz (Orgs).

Religión, cultura y política en las sociedades del siglo XXI. Buenos Aires: Biblos, 2013. p. 137-158.

TEIXEIRA, Faustino. O Censo de 2010 e as religiões no Brasil: esboço de apresentação. In: TEIXERIA, Faustino; MENEZES, Renata (Org.). Religiões em movimento: o Censo de 2010. Petrópolis: Vozes, 2013. p. 17-35.

TILLICH, Paul. La mia ricerca degli assoluti. Roma: Ubaldini, 1968.

TORRES, Bolívar. Os mil nomes de Gaia: a necessidade de repensar a relação do homem com o planeta. O Globo, Rio de Janeiro, Cultura, 13 set. 2014. Disponível em:

<http://oglobo.globo.com/cultura/livros/os-mil-nomes-de-gaia-necessidade-de-repensarrelacao-do-homem-com-planeta-13917326\#ixzz3HuftHKTT>. Acesso em: 14 set. 2014.

VIGIL, José Maria. O sedutor futuro da teologia. In: VIGIL, José Maria (Org). Por uma teologia planetária. São Paulo: ASETT EATWOTT / Paulinas, 2011. p. 267-277.

VIVEIROS DE CASTRO, Eduardo. Encontros. Rio de Janeiro: Beco do Azougue, 2007. (Organização de Renato Sztuman).

WILLAIME, Jean-Paul. Du religieux autrement. Le monde des religions, Paris, n. 55, p. 23, septembre/octobre 2012. 